\title{
Production of Bioethanol from Fruit Wastes (Banana, Papaya, Pineapple and Mango Peels) Under Milder Conditions
}

\section{Mohammad Jahid, Akanksha Gupta and Durlubh Kumar Sharma}

Centre for Energy Studies, Indian Institute of Technology Delhi, New Delhi, India

*Corresponding author: Durlubh Kumar Sharma, Centre for Energy Studies, Indian Institute of Technology Delhi, New Delhi, India, Tel: +91-11-26591256; E-mail: sharmadk28ces@gmail.com

Received date: April 26, 2018; Accepted date: May 07, 2018; Published date: May 14, 2018

Copyright: (c) 2018 Jahid M, et al. This is an open-access article distributed under the terms of the Creative Commons Attribution License, which permits unrestricted use, distribution, and reproduction in any medium, provided the original author and source are credited.

\begin{abstract}
Fruit wastes are available in plenty as wastes world over. In fact, there is a need to recover value added products from these wastes. Fruit wastes are rich in sugars and carbohydrates which can be recovered and utilized for the production of bioethanol. Gasoline is being used at very huge scales globally. Therefore, plenty of bioethanol would be required to be produced if bioethanol has to replace gasoline. Present studies are directed towards finding cost effective ways to recover sugars from fruit wastes firstly without using any acidic or enzyme catalysts. Fruit wastes such as peels of banana (BP), pineapple (PAP), papaya (PP) and mango (MP) were used for studying their potential to yield total reducing sugars (TRS), pentose sugars (PS) and bioethanol. Simple soaking in water and steaming resulted in the recovery of free sugars. Enzymatic hydrolysis using cellulase and xylanase enzymes resulted in giving good yields of total reducing sugars and pentose sugars. BP and PAP were found to be the potential candidates for the production of bioethanol. In comparison to the enzymatic hydrolysis the dilute $\mathrm{H}_{2} \mathrm{SO}_{4}$ hydrolysis was found to give higher yields of TRS and PS from fruit wastes. However, the enzymatic hydrolysis was found to be a better choice for the production of bioethanol from the BP and PAP hydrolyzates in order to avoid the effect of yeast toxicants produced. Simple water soaking and steaming was found to be an inexpensive way to recover free sugars from fruit wastes. Enzymatic hydrolysis followed by fermentation using Saccharomyces cerevisae was found to produce bioethanol from the water-steam pretreated fruit wastes. Possible mechanism of enzymatic hydrolysis is suggested. Effect of enzyme concentration on the hydrolysis of PAP and BP for different times at $50^{\circ} \mathrm{C}$ was studied. Fruit wastes could be exploited as potential source of bioethanol.
\end{abstract}

Keywords: Fruit peels; Fermentable sugars; Enzymatic hydrolysis; Acidic hydrolysis; Bioethanol

\section{Introduction}

Excessive use of fossil fuels has resulted in the global warming and climate change. Therefore there is a thrust towards replacing fossil fuels with cleaner and renewable fuels such as bioethanol and biodiesel. Moreover due to the rapid consumption of conventional fossil fuels and their unpredictable change in prices there is an urgent need to develop an alternative renewable source of energy e.g., bioethanol for the national energy securities. Lignocellulosic raw materials which include fruit and vegetable waste, forestry waste, agroresidues, MSW etc. can be used to produce bioethanol. Fruit wastes are a rich source of natural sugars. Huge amount fruits are consumed world over as health supplements and even as functional foods [1]. World fruit production in 2012 was 636,545,000 tonnes, out of which China produced the maximum (21.2\%) followed by India (12.6\%) and then Brazil (5.9\%). Fruit wastes are rich in cellulose and hemicellulose and have low lignin contents, which are mostly loosely placed there between cellulose and hemicelluloses. This makes these wastes interesting for bioethanol production. Lignocellulosic raw materials are considered renewable source of energy and their use for bioethanol production may also help in $\mathrm{CO}_{2}$ mitigation.

According to FAO, out of the global food waste, $40-50 \%$ comes from fruits, root crops and vegetables. In Asia, fruits and vegetable wastes alone account for $37 \%$ of the total agricultural waste. Every year, there is a loss of about $35-40 \%$ of fruits and vegetables as wastes. Even after consumption, fruit storage and industrial processing plenty of fruit waste is generated and its management is also a problem.

\section{Need for enhancing scale of bioethanol production}

Bioethanol has a great advantage over conventional fuels. It has higher octane rating and it is safer to use. Air quality will improve by its clean and proper burning quality. There are national policies for blending 20-30\% ethanol in gasoline in different countries by 2030 . However, the availability of ethanol is still a challenge. In fact, oil is consumed at much larger scales of 95 million barrels/day in the world. It is proposed to replace the use of oil with renewable biofuels such as biodiesel and bioethanol. However production of these fuels from crops such as oil seeds, wheat or rice starch, sugar canes etc. at such a scale would be another challenge because of the availability of feedstock's at that much scales. Moreover, the use of these conventional feedstocks could lead to food versus fuel controversies. The use of agro residues, forest residues or MSW etc. would also generate only a limited amount of bioethanol. Therefore, there is a need to explore the use of other wastes such as, fruit wastes or vegetable wastes which are consumed at huge scales. In fact, fruits are rich in sugars therefore fruit wastes could be a good source of fermentable sugars and bioethanol. Every fruit generates $50 \%$ of its weight as a waste after its consumption, which is a huge amount and its utilization to generate bioethanol would help in not only solving the problem of energy security but this may also help in solving the problem of waste management [2]. 


\section{Fruit wastes as a source of bioethanol}

Itelima et al. estimated bioethanol production by simultaneous saccharification and fermentation from banana, plantain and pineapple peels by co-culture of $A$. niger and $S$. cerevisiae [3]. Singh et al. have studied the simultaneous saccharification and fermentation (SSF) at different temperature $\left(20^{\circ} \mathrm{C}\right.$ to $\left.50^{\circ} \mathrm{C}\right)$ of banana peels to obtain bioethanol by using co-cultures of $A$. niger and $S$. cerevisiae at different $\mathrm{pH}$ (4 to 7) for seven days fermentation for bioethanol and reducing sugar estimation [4]. In this study it was observed that the optimum $\mathrm{pH}$ and temperature for the fermentation of banana peels was 6 and $30^{\circ} \mathrm{C}$. With these optimum conditions of $\mathrm{pH}$ and temperature, different yeast concentrations of $3 \%$ to $12 \%$ were used for performing fermentation and it was found that the time required for the accomplishment of fermentation reduced dramatically.

Grohmann et al. have studied the use of cellulase enzyme for hydrolysis of cellulose of banana peels and observed that the maximum saccharification was achieved with a cellulase enzyme from Trichoderma reesei QM 9414 [5]. Mishra et al. investigated the production of bioethanol from fruit peels of orange, sweet lime and pineapple. Pineapple produced the maximum sugar fruit wastes [6].

Reddy et al. have investigated that mango peels contain larger amounts of reducing sugars up to $40 \%$ (w/v) [7]. Direct fermentation of mango peels yielded very low content of bioethanol about 5.4\% $(\mathrm{v} / \mathrm{v})$. It was reported in this study that this can be enhanced up to $7.14 \%(\mathrm{w} / \mathrm{v})$ by using nutrient supplementation such as yeast extract, bran extract, peptone and wheat.

Arumugam and Manikandan evaluated the chemical composition of banana and mango fruit waste for bioethanol production [8]. In this study dilute acid pretreatment was followed by enzymatic hydrolysis and maximum sugar was produced from the mixed fruit pulps, followed by the banana fruit pulp and then followed by banana peels. They reported that hydrolysate from enzyme shows fermentation efficiency about $70.3 \%$ compared to $27.1 \%$ of hydrolysate from acid hydrolysis after $48 \mathrm{~h}$ of incubation. The authors have reported that production of bioethanol was far better from enzyme hydrolysate than that from acid hydrolysate with $S$. cerevisiae. Several other workers have reported on the use of fruit wastes for the production of bioethanol [9-14]. However, there is a need to develop a convenient process of enzymatic hydrolysis of fruit wastes by firstly recovering the easily recoverable sugars by milder water-steam treatment. This would avoid biochemical or chemical treatment for the easily recoverable sugars and this would also make the enzymatic hydrolysis of remaining hemicellulosic and cellulosic biopolymers convenient and easier without much inhibitions. Presently, studies have been extended on the production of bioethanol from fruit wastes through enzymatic hydrolysis using commercial cellulase and xylanase enzymes after milder pretreatment with water-steam. A comparison of enzymatic hydrolysis of fruit wastes with their acidic hydrolysis has also been made. Research work on the enzymatic hydrolysis of agroresidues and petrocrop spent residues has been reported from the authors, laboratory in the past which included the work on the production of cellulose enzyme and the production of bioethanol by enzymatic hydrolysis [15-19]. Research work on the acidic hydrolysis of agroresidues and the petrocrop spent residues was also extended in the authors, research laboratory in the past [20-23]. In fact, Sharma and Godstein have reported the research work on the acidic hydrolysis of lignocellulosic biomass (LCB) and then utilization of lignins thus obtained as well [24]. Presently attempts have been made to briefly review the research work on the production of bioethanol from the lignocellulosic wastes such as fruit wastes in order to bring out the need of more research work in the area of the process development engineering in this field.

\section{Important factors in production of bioethanol from fruit wastes}

A crucial step in the bioconversion of lignocellulosic feedstocks to biofuels is to cost effectively maximize the saccharification of the cellulose and hemicellulose components to fermentable sugars. One of the challenges is the still too high enzyme costs involved in the saccharification of the cellulosic component and, to a lesser extent, the loss of some of the hemicellulosic sugars during pretreatment. Thus, in many pretreatment strategies such as steam explosion, mild severity conditions are often used to avoid, or at least minimize, sugar loss during pretreatment. Under these milder pretreatment conditions, some of the hemicellulose, mostly xylan in agricultural residues and hardwood, remains associated with the cellulosic-rich water insoluble fraction. However, this residual hemicellulose component is known to exert a significant influence on the effectiveness of enzymatic hydrolysis of its cellulosic component [2]. Recently research work on the production of value added fuels and chemicals from biomass have been reviewed from the author's laboratory [25]. Liguori et al. have also recently reviewed the research work on the different bioreactors used for the conversion of different lignocellulosic biomass including fruit wastes to obtain fermentable sugars, bioethanol and other value added products [26].

As already known, the main factors affecting enzymatic hydrolysis are substrate concentration and enzyme loading, beside various other factors. These two factors mainly affect the enzyme activity and product yield. In this study, the effect of substrate loading as well as enzyme loading was also studied, whereby, the response was reported in terms of total reducing sugars (TRS) and pentose sugars (PS) liberated at the end of the treatment.

The other problem with enzymatic hydrolysis of lignocellulosic biomass, such as, agro residues, forest wastes, sawdust, wood wastes, aquatic biomass etc., is the presence of lignin in significant amounts, i.e., exceeding $15 \%$ mostly. Lignin hampers the accessibility of cellulase to the substrate, thus it is required to remove it prior to enzymatic hydrolysis. However, fruit wastes mostly contain lesser amounts of lignin and these contain free sugars besides the hemicelluloses and cellulosic biopolymers, therefore research work on the hydrolysis of fruit wastes was extended presently. Present authors have attempted to study the effect of different concentration of cellulase and xylanase on the hydrolysis of mildly pretreated fruit wastes (fruit peels) for different lengths of time and compared the same with acidic hydrolysis under relatively milder conditions. Pretreatment conditions were kept mild i.e., water soaking followed by steaming for $15 \mathrm{~min}$. which had also led to the recovery of free sugars available in peels. It seems there is a need to extend research work in this direction in order to develop the process of obtaining bioethanol from fruit peels and not much work seems to have been done in this direction.

\section{Materials and Methods}

\section{Preparation of raw materials}

Fruit peels samples of banana peels (BP), pineapple peels (PAP), papaya peels (PP) and mango peels (MP) were collected from the local whole sale fruit market near Indian Institute of Technology Delhi, 
Hauz Khas, New Delhi, India. The fruit peels were reduced to $1-2 \mathrm{~cm}$ long pieces to make it easier to handle. They were sun dried and then oven dried overnight $60^{\circ} \mathrm{C}$. The dried substrate was ground to a mash size of 40 , packed in polyethylene bags and stored at $0^{\circ} \mathrm{C}$ temperature for further analysis. The samples were then analyzed for proximate and chemical composition analysis to analyse the amount of cellulose, hemicelluloses, lignin, ash and moisture. Cellulose was measured via the anthrone method [27]. Hemicellulose and lignin were estimated using NREL procedures [28].

\section{Pretreatment of fruit wastes}

The fruit wastes i.e., fruit peels $(20 \mathrm{~g})$ were soaked in water $(200 \mathrm{ml})$ for $30-180 \mathrm{~min}$. and then autoclaved in steam at $120^{\circ} \mathrm{C}$ for $15 \mathrm{~min}$. The pretreated wastes were filtered and the filtrate obtained was analyzed for the total reducing sugars (TRS) and pentose sugars (PS).

The pretreated solid fruit waste substrate obtained from the above treatment was dried and used for the subsequent hydrolysis studies using commercial cellulase or xylanse enzymes separately as well as for the acidic hydrolysis.

About $5 \mathrm{~g}$ of dried fruit wastes (peels) or dried pretreated fruit wastes (peels) were used for the experiments in the present work.

\section{Enzymatic saccharification}

The enzymes used for this process were Cellulase from T. reesei (Sigma Aldrich) and Xylanase from Thermomyces lanuginosus (Sigma Aldrich). The hydrolysis was performed in $50 \mathrm{mM}$-citrate buffer ( $\mathrm{pH}$ 4.8) at $45^{\circ} \mathrm{C}$ in Stoppered $100 \mathrm{ml}$ flask with general agitation at 100 $\mathrm{rpm}$. The experimental set up was incubated for 48 to $72 \mathrm{~h}$ with sample collection at a regular time interval of $6 \mathrm{~h}$. The samples were centrifuged at $10000 \mathrm{rpm}$ for $5 \mathrm{~min}$ at $4^{\circ} \mathrm{C}$ and the supernatant was collected and filter sterilized. The hydrolysate was filter sterilized and collected in screw-cap bottles to be stored at $4^{\circ} \mathrm{C}$ until further use. Estimation of total reducing sugar (TRS) in the hydrolysate of biomass was done by DNS method and the estimation of pentose sugar (PS) was done by Patrisha et al. [10,29,30].

\section{Analysis of sugars produced}

The reducing sugars and pentose sugar contents were determined on liquid aliquots of fruit peels by DNS and Orcinol method with spectrophotometer at $540 \mathrm{~nm}$ and $670 \mathrm{~nm}$ respectively for sugar analysis.

All determinations were done in duplicate in case hydrolysis with cellulase as well as xylanase enzymes. The saccharification process could be performed without changing the $\mathrm{pH}$ value of substrate, as $\mathrm{pH}$ of the wastes is ideal for the activity of cellulolytic enzymes.

\section{Enzymatic hydrolysis of PAP and BP using cellulase enzyme}

It was observed in reference experiments of cellulase enzyme hydrolysis with $45 \mathrm{IU} / \mathrm{g}$ concentration. Maximum saccharification was observed with 5\% SL in PAP and BP. Therefore, this has been selected for further experiments with PAP and BP in which maximum sugars were observed. Enzymatic saccharification was carried out by using commercial cellulase enzyme and the hydrolysis was performed in 50 $\mathrm{mM}$-Citrate buffer $(\mathrm{pH} 4.8)$ at $45^{\circ} \mathrm{C}$ in stoppered $100 \mathrm{ml}$ flask with general agitation at $100 \mathrm{rpm}$. The volume was adjusted to achieve biomass loading of $5 \%$ (weight by volume). The experimental set up was incubated for $36 \mathrm{~h}$ at $50^{\circ} \mathrm{C}$ with sample collection at a regular time interval of $6 \mathrm{~h}$. Enzyme concentration of cellulase/ xylanase of 20-40-60-80-100 IU/g gram dry biomass was used for these experiments. The saccharification process can be performed without changing the $\mathrm{pH}$ value of substrate, as $\mathrm{pH}$ of the wastes is ideal for the activity of cellulolytic and pectinolytic enzymes. The sugar hydrolysate was obtained by centrifugation. In fact, the hydrolysate was first centrifuged at $10000 \mathrm{rpm}$ for $5 \mathrm{~min}$ at $4^{\circ} \mathrm{C}$. The supernatant was collected and filter sterilized. The hydrolysate was collected in screwcap bottles and stored at $4^{\circ} \mathrm{C}$ until further use. The total reducing sugars and pentose content for each sample were measured by using DNS and Orcinol method respectively.

\section{Enzymatic hydrolysis of PAP and BP using xylanase enzyme}

Enzymatic saccharification by commercially available XE was carried out by using commercial xylanase enzyme. The hydrolysis was performed in $50 \mathrm{mM}$ - Citrate buffer $(\mathrm{pH} 4.8)$ at $50^{\circ} \mathrm{C}$ in stoppered 100 $\mathrm{ml}$ flask with general agitation at $120 \mathrm{rpm}$. The volume was adjusted to achieve biomass loading of $5 \%(\mathrm{w} / \mathrm{v})$. The experimental set up was incubated for $36 \mathrm{~h}$ with sample collection at a regular time interval of 6 h. Xylanase EC of 40-80-120-160-200 IU/ gram dry biomass of 5\% SL was used. The saccharification process can be performed without changing the $\mathrm{pH}$ value of substrate, as $\mathrm{pH}$ of the wastes is ideal for the activity of cellulolytic and pectinolytic enzymes.

The sugar hydrolysate was obtained by centrifugation. The hydrolysate was first centrifuged at $15000 \mathrm{rpm}$ for $5 \mathrm{~min}$ at $4^{\circ} \mathrm{C}$. The supernatant was collected and filtered and sterilized. The hydrolysate was collected in screw-cap bottles and stored at $4^{\circ} \mathrm{C}$ until further use. The total reducing sugars and pentose sugars content for each sample were measured by using DNS and Orcinol methods respectively.

\section{Acidic hydrolysis of pretreated fruit wastes}

Pretreated fruit peels (5 g) were taken in the conical flasks containing the dilute $\mathrm{H}_{2} \mathrm{SO}_{4}$ in different concentrations from $0.5 \%, 1 \%$, $2 \%$ and $3 \%$ in about twice the weight/volume i.e., $10 \mathrm{ml}$. This was mixed well, and the peels were allowed to soak for a period from 30 min to $180 \mathrm{~min}$. There after these were autoclaved at $121^{\circ} \mathrm{C}$ for different periods from $15 \mathrm{~min}$ to $60 \mathrm{~min}$ for different experiments.

The liquid hydrlysates from autoclave were then neutralised and recovered from the hydrolysis process. The gydrolysates samples were centrifuged at $15000 \mathrm{rpm}$ for $10 \mathrm{~min}$. at $4^{\circ} \mathrm{C}$. The solid fraction was washed with distilled water and dried in hot air oven at $72^{\circ} \mathrm{C}$. The supernatant was collected and used for the determination of TRS and pentose sugars as described before.

\section{Fermentation of reducing sugars to obtain bioethanol}

Fermentation of total reducing sugars and pentoses and estimation of ethanol was carried out by using the Bakers yeast by following the standard procedure $[8,31]$ and the ethanol was estimated by potassium dichromate method [32].

\section{Results and Discussion}

In fact, plenty of fruit wastes such as banana peels (BP), pineapple peels (PAP), papaya peels (PP) and mango peels (MP) are available world over and these just pose a problem of their waste management to the authorities. However, these fruit wastes have, firstly, free sugars available, and secondly, most of these wastes have less than $10 \%$ lignin. 
Citation: Jahid M, Gupta A, Sharma DK (2018) Production of Bioethanol from Fruit Wastes (Banana, Papaya, Pineapple and Mango Peels)

Page 4 of 11

Presently attempts have been made firstly to recover free sugars through aqueous extractions under moderate conditions. Further studies have been carried out to subject aqueous treated fruit wastes to enzymatic hydrolysis using commercial cellulase as well as xylanase enzymes.

Initially, the fruit waste was analyzed for cellulose, hemicellulose and lignin content, to assess which route would be best suited for the hydrolysis and subsequent bioethanol production. Table 1 shows the chemical composition of fruit wastes. The least lignin content $(2.7 \%)$ was found in papaya peels and the maximum in mango peels $(27.9 \%)$. The maximum cellulose content was found in mango peels $(38.4 \%)$ and the least in papaya peels $(20.4 \%)$. The overall lignin content in the samples taken for study was found to be low enough to proceed for direct enzymatic hydrolysis. Banana peels contained maximum ash $(12.9 \%)$, with the least in mango peels $(4.0 \%)$.

\section{Water-steam treatment of BP, PP, PAP and MP}

Studies were initially carried out to recover free carbohydrates present in fruit wastes by soaking these in water for a time period of $30-180 \mathrm{~min}$. followed by autoclaving at $120^{\circ} \mathrm{C}$ for $15 \mathrm{~min}$ using $5 \%$ and $10 \%$ solid or substrate loading (SL) of fruit wastes. Figure 1a shows the production of total reducing sugars and pentose sugars by using $5 \% \mathrm{SL}$ in this pretreatment. Figure $1 \mathrm{~b}$ shows the production of total reducing sugars and pentose sugars by using $10 \%$ SL of fruit wastes in the watersteam pretreatment.

\section{(a)}

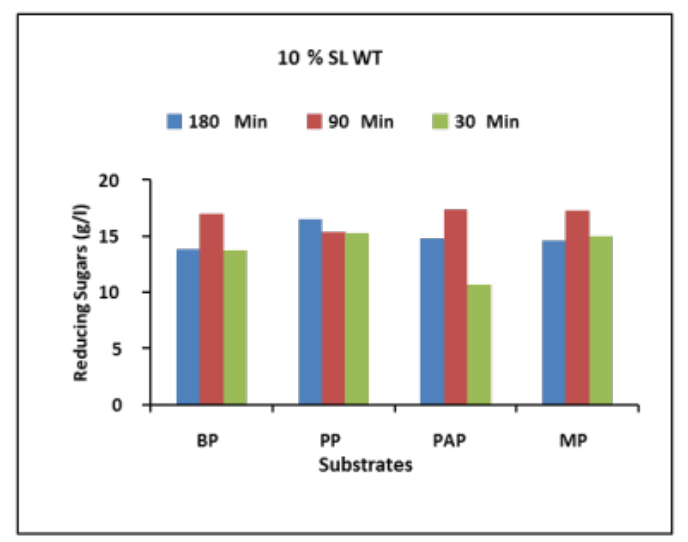

(b)

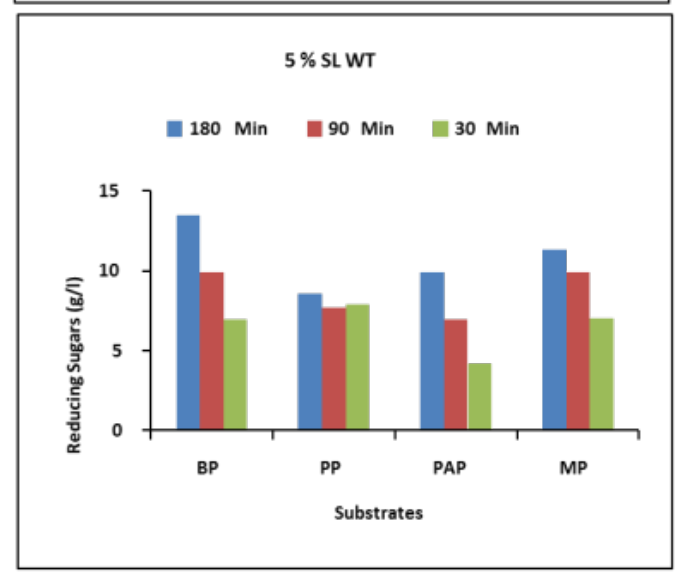

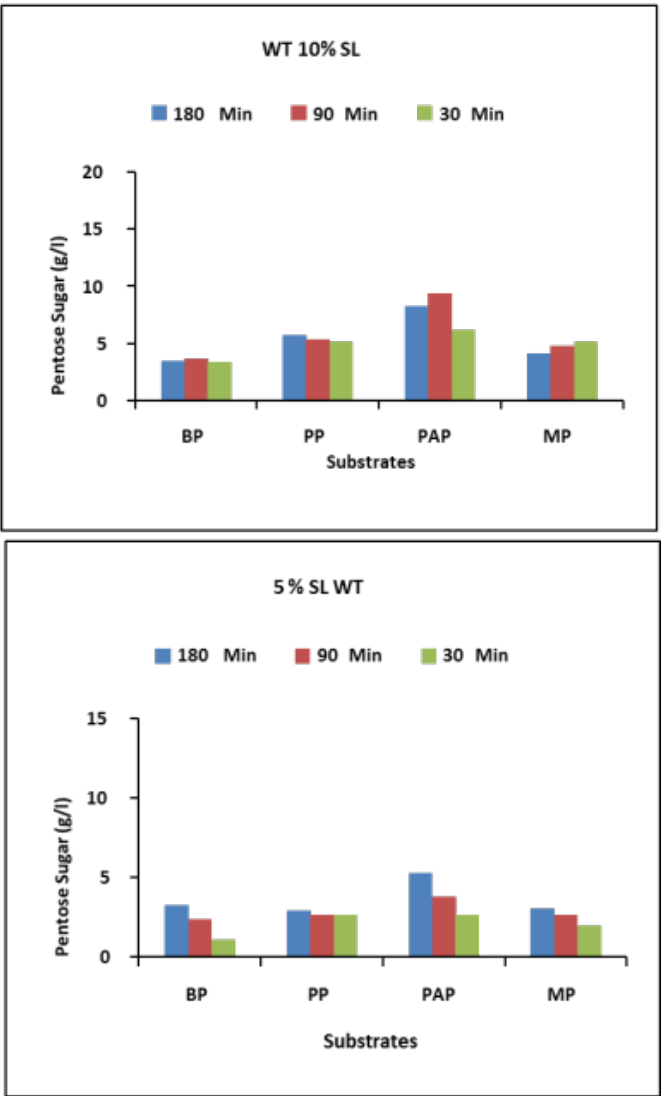

Figure 1: Production of total reducing sugars (TRS) and pentose sugars (PS) from the water steam treatment of (a) 10\% substrate loading (SL) (b) $5 \%$ substrate loading (SL) of fruit wastes.

Results show the effects of time and substrate loading during watersteam treatment of BP, PP, PAP and MP. Firstly reducing sugars produced were monitored. In case of 5\% SL it was found that BP was observed to give the maximum sugar production as $13.5 \mathrm{~g} / \mathrm{l}$. followed by MP as $11.6 \mathrm{~g} / \mathrm{l}$ with soaking time of $180 \mathrm{~min}$ and autoclave for 15 $\min$ at $120^{\circ} \mathrm{C}$.

During the study, effects of time and substrate loading (SL) after water-steam pretreatment of PAP was observed and in the present study, $10 \%$ SL with 90 min soaking time produced the maximum total reducing sugars e.g., $17.3 \mathrm{~g} / \mathrm{l}$ along with $9.4 \mathrm{~g} / \mathrm{l}$ PS. This could be possibly due to the reason that simpler free sugars present in fruit waste biomass materials can be easily recovered without any chemical or biological treatment and without any degradation. Results show that fruit peels have good amounts of free reducing sugars which can be easily recovered without any chemical and biological treatment or severe physical treatment, which makes these biomass materials a good feedstock for bioconversion to bioethanol. It could also be possibly due to low inhibitory lignin contents present in most if the fruit waste biomass. 


\section{Enzymatic hydrolysis using commercial cellulose}

Using $1 \%$ and $3 \%$ substrate loading (SL): Enzymatic hydrolysis of fruit waste has potential for production of bioethanol. Though, it may not be the sole source, but it does seem to have potential as a supplement for conventional feedstocks. The enzymatic hydrolysis was carried out using the aforementioned pretreated fruit wastes at $45^{\circ} \mathrm{C}$, using $45 \mathrm{IU} / \mathrm{g}$ concentration (as is normally used) in $100 \mathrm{ml}$ Erlenmeyer flasks along with gentle agitation of $100 \mathrm{rpm}$. These are the normal optimum conditions used for the enzymatic hydrolysis using cellulose enzyme.

Cellulase and Xylanase were separately administered to each sample and the sugars produced were reported as total reducing sugars (TRS) and pentose sugars (PS). Pentose sugars were analyzed because the samples were found to have significant hemicellulose content. The final aim was to achieve complete utilization of fermentable sugars to maximize production of bioethanol. Effect of substrate loading (SL) was also monitored along with time. Cellulase concentration was initially set at $45 \mathrm{IU} / \mathrm{g}$ dried biomass. The results have been shown in the (Figures 2a-2e). Figures $2 \mathrm{a}$ and $2 \mathrm{e}$ show the effect of substrate loading on enzymatic hydrolysis of fruit wastes using cellulase enzyme using. All the samples gave higher amounts of TRS and PS, when substrate loading was kept at 5\%. Further increase in SL may result in a plateau due to substrate inhibition of the enzyme. From the Figures $2 \mathrm{a}-2 \mathrm{e}$, it can be observed that in general, 12-18 h time was sufficient for maximum hydrolysis in terms of TRS and PS.

In case of mango peels, the maximum saccharification was observed with $1 \% \mathrm{SL}$ as $5.0 \mathrm{~g} / \mathrm{l}$ with comparatively low pentose content $0.778 \mathrm{~g} / \mathrm{l}$ after $18 \mathrm{~h}$ of reaction time followed by BP $3.98 \mathrm{~g} / \mathrm{l}$ reducing sugars and the pentose content was found to be $1.311 \mathrm{~g} / \mathrm{l}$ at $12 \mathrm{~h}$ time at $45^{\circ} \mathrm{C}$ (Figure 2a). Higher pentose content in case of BP could be possible due to the fact that less degradation of pentose took place. Results obtained from PAP and PP by enzymatic hydrolysis are also satisfactory by the amount of reducing sugars are less than those of BP and MP in 1\% SL (Figure 2a). The maximum total reducing sugars were observed in case of PAP and PP also after $12 \mathrm{~h}$.

It was observed that mango peels are giving better results than other and those after $12 \mathrm{~h}$ of hydrolysis time. The maximum saccharification was observed with $1 \% \mathrm{SL}$ as $12.3 \mathrm{~g} / \mathrm{l}$ with a comparatively low pentose content $1.88 \mathrm{~g} / \mathrm{l}$ after $12 \mathrm{~h}$ of reaction time followed by PAP $(11.7 \mathrm{~g} / \mathrm{l}$ TRS $s$ and the pentose content was found to be $7.3 \mathrm{~g} / \mathrm{l}$ at $18 \mathrm{~h}$, time at $45^{\circ} \mathrm{C}$. Higher pentose content in case of PAP could be possible due to the reason that less degradation of pentose had taken place and another factor may be the higher percentage of hemicellulose amount in PAP. Results obtained from BP and PP by enzymatic hydrolysis were also found to be comparable from the amount of reducing sugars which were less than those from PAP and MP in 3\% SL. The maximum reducing sugars were observed in case of $\mathrm{BP}$ and $\mathrm{PP}$ also at $12 \mathrm{~h}$ (Figure 2b).

Using 5\% SL: It was decided to increase the SL of fruit waste peels to $5 \%$. The maximum saccharification was observed in PAP with 5\% SL as $17.3 \mathrm{~g} / \mathrm{l}$ with high pentose content $11.1 \mathrm{~g} / \mathrm{l}$ after $12 \mathrm{~h}$ of reaction time followed by that of BP $16.25 \mathrm{~g} / \mathrm{l}$ total reducing sugars and the pentose content was found to be $2.8 \mathrm{~g} / \mathrm{l}$ at $12 \mathrm{~h}$ time at $45^{\circ} \mathrm{C}$ (Figure $2 \mathrm{c}$ ). Higher pentose content in case of PAP could be possible due to the less degradation of pentose takes place and higher percentage of hemicellulose amount in PAP. Results obtained from BP and PAP by enzymatic hydrolysis are also satisfactory considering the fact that the amount of reducing sugars produced are less than those from PAP and
PP using 5\% SL (Figure 2c). The maximum reducing sugars were observed in case of BP and PAP also at $12 \mathrm{~h}$, after observing the results it was decided that the further processing of fruit wastes should be carried out by using 5\% SL for enzymatic hydrolysis, because 5\% SL with $45 \mathrm{IU} / g$ produced the maximum reducing sugars. Presently the results obtained were found to be comparably fine and no attempts were made to make the pretreatment conditions severe and on increasing the SL further. However, it is known that there is a potential to increase the SL further $10 \%$ and beyond also and even adapting surface culture techniques when the reducing sugars are simultaneously produced [33]. The yield of reducing sugars can vary from different fruits depending upon several factors including the degree of ripeness and other genetic differences of the seeds and climate or soil conditions etc. A few workers have reported higher yields of reducing sugars from the fruit peels as well which is also quite possible depending upon the sweetness of the fruits and other factors described before, however, the presently the emphasis was more on the process development engineering of obtaining reducing sugars and bioethanol as a biofuels from fruit wastes in general as stated before and understand the mechanism of the enzymatic hydrolysis of fruit wastes and lignocellulosic biomass.

\section{Effect of enzyme concentration (EC)}

It was decided to increase the temperature of biocatalytic hydrolysis to $50^{\circ} \mathrm{C}$ and vary the biocatalyst concentration i.e., cellulase enzyme concentration to study if this could reduce the hydrolysis time. In fact, work on the production of biocatalysts at higher temperatures is also being extended. Olajuigbe and Ogunyewo have recently reported the production and use of thermostable cellulase enzyme having stability from $50-90^{\circ} \mathrm{C}[34]$.

Presently, the pretreated PAP at 5\% SL was subjected to hydrolysis using different EC of commercial cellulase enzymes for a different length of time at $50^{\circ} \mathrm{C}$. The results have been shown in Figure $2 \mathrm{~d}$. It was found that when the cellulase EC of $60 \mathrm{IU} / \mathrm{g}$ was used then the maximum TRS yield of $20 \mathrm{~g} / \mathrm{l}$ was obtained and the PS yield was $9.2 \mathrm{~g} / \mathrm{l}$ after $12 \mathrm{~h}$ hydrolysis time. The results are shown in Figure $2 \mathrm{~d}$. These may be thus the optimum conditions for obtaining the maximum yields of TRS and PS from the pretreated PAP. However, here enzyme loading was found to be higher at $50^{\circ} \mathrm{C}$ but the time of hydrolysis had reduced. These studies may be helpful in the future process intensification and scale up studies.

Similarly, studies were further extended to find out the effect of cellulase EC on the hydrolysis of pretreated BP using 5\% SL. The results have been shown in Figure 2E. The cellulase enzyme was observed to be effective in the pretreated BP samples, probably because of the considerably good cellulosic percentage (Table 1). It was found that more than $12 \mathrm{~h}$ hydrolysis at $50^{\circ} \mathrm{C}$ improved the final sugar yields and it was $21.9 \mathrm{~g} / \mathrm{l}$ TRS with $9.2 \mathrm{~g} / \mathrm{l}$ PS by using $60 \mathrm{IU} / \mathrm{g}$ EC of cellulase enzyme. As a consequence, peel was submitted to 18 and $24 \mathrm{~h}$ hydrolysis at $50^{\circ} \mathrm{C}$ (Figure 2e). The high temperature, higher enzyme loading and longtime was found to be favorable for maximum sugar yield. The optimal time-temperature of $18 \mathrm{~h}$ and $50^{\circ} \mathrm{C}$ for cellulolytic hydrolysis of BP were observed, as can be seen from Figure 2e. 


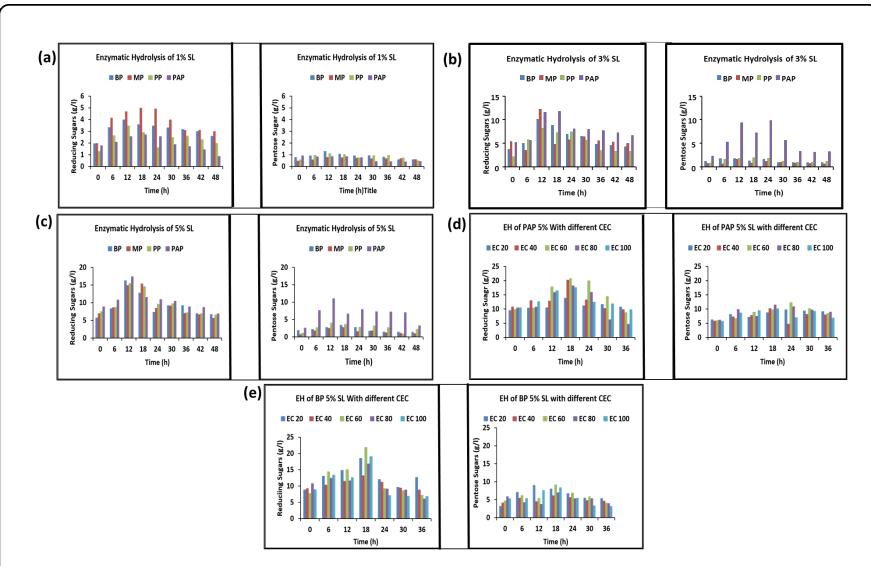

Figure 2: Estimation of TRS and PS content in (a) 1\% (b) 3\% (c) 5\% SL by using commercial cellulase enzyme and Estimation of TRS and PS content in (d) PAP 5\% SL (e)BPH 5\% SL by using different concentration of commercial cellulase enzyme.

\section{Enzymatic hydrolysis using xylanase (XE)}

In fact, $\mathrm{Hu}$ et al. have reported on the importance of the xylanase enzyme in enhancing the hydrolysis of lignocellulosic biomass by showing a synergistic action along with cellulose enzyme by increasing its accessibility, fiber swelling and porosity [2]. Therefore, presently it was decided t-he enzymatic hydrolysis of pretreated fruit wastes i.e., PAP and BP using xylanase enzyme as the fruit wastes contained considerable amounts of hemicellulose contents. It was decided to increase the temperature of biocatalytic hydrolysis to $50^{\circ} \mathrm{C}$ and vary the biocatalyst i.e., xylanase enzyme concentration to study if this could reduce the hydrolysis time. The results have been shown in Figures $3 \mathrm{a}$ and $3 \mathrm{~b}$.

\section{Analysis of hydrolysate of PAP}

Hydrolysis with commercial xylanase was carried out at $50^{\circ} \mathrm{C}$ for the time intervals of $0-36 \mathrm{~h}$, by using different $\mathrm{EC}$ in order to gain the highest yield of reducing sugars. The enzymes tested was found to be quite effective in these peel samples, probably because of the considerably good fraction of the materials which contribute to reducing sugars (Table 1). Moreover, the results obtained showed that more than $12 \mathrm{~h}$ of hydrolysis at $50^{\circ} \mathrm{C}$ improved the final sugar yield. The results have been shown in Figure $3 \mathrm{a}$. It was observed that using xylanse EC of $80 \mathrm{IU} / \mathrm{g}$ after $24 \mathrm{~h}$ of hydrolysis time, $16.6 \mathrm{~g} / \mathrm{l}$ TRS and $10.2 \mathrm{~g} / \mathrm{l}$ content of pentose sugars was obtained, and this was followed by those obtained as the $14.12 \mathrm{~g} / \mathrm{l}$ TRS and $8.8 \mathrm{~g} / \mathrm{l}$ pentose sugars by using $120 \mathrm{IU} / \mathrm{g}$ of xylanase enzyme for hydrolysing the PAP after $18 \mathrm{~h}$. Here again the enzyme loading required was high for the shorter hydrolysis time.

Higher pentose contents could be due to the reason that the xylanase is acting mainly on the pentosans of the hemicellulose of the PAP, and it could also be possibly due to higher hemicellulose fraction present in PAP (Table 1).

Results from the Figure 3a show the effect of SL, time and enzyme concentration (EC) during the enzymatic saccharification of PAP using xylanase enzyme. It was found that at $18-24 \mathrm{~h}$ the maximum saccharification was observed for PAP.

\section{Hydrolysis of BP using xylanase (XE)}

The results of control samples indicated that peels from banana are a suitable substrate for fermentation i.e., potentially used as a carbon source for fermentation. Hydrolysis of pretreated BP was carried out at $50^{\circ} \mathrm{C}$, using different EC of xylanase enzyme at time intervals of 0-6-12-18-24-30-36 h, in order to obtain the highest yield of reducing sugars. The results have been shown in Figure $3 \mathrm{~b}$. It was found that hydrolysis for $12 \mathrm{~h}$ at $50^{\circ} \mathrm{C}$ was found to be good for obtaining the yield of $14.5 \mathrm{~g} / \mathrm{l}$ TRS and $8.5 \mathrm{~g} / \mathrm{l}$ of pentose sugar by using $160 \mathrm{IU} / \mathrm{g}$ at $12 \mathrm{~h}$ and then it started to decrease with time after $12 \mathrm{~h}$ (Figure $3 \mathrm{~b}$ ).

As a consequence, $\mathrm{BP}$ was subjected to 6 and $18 \mathrm{~h}$ hydrolysis at $50^{\circ} \mathrm{C}$ (Figure $3 \mathrm{~b}$ ). The optimal time-temperature of $12 \mathrm{~h}$ at $50^{\circ} \mathrm{C}$ for obtaining maximum sugar yields by using the xylolytic hydrolysis were thus found and these may help in the future process intensification studies.

Relatively low pentose sugar contents could be possibly due to low hemicellulose fraction present in BP (Table 1). Results in Figure 3b show the effect of SL, time and EC during the enzymatic saccharification of BP using xylanase enzyme. It may be understood that at $12 \mathrm{~h}$ the maximum saccharification was observed for BP. On the basis of present study BP and PAP substrates which produced maximum sugars in enzymatic hydrolysates were selected for fermentation by baker's yeast ( $S$. cerevisiae).

\begin{tabular}{|l|l|l|l|l|l|l|l|l|}
\hline Fruit waste & $\begin{array}{l}\text { Hemicellulose } \\
\text { basis) }\end{array}$ & $\begin{array}{l}\text { (\% on dried } \\
\text { Cellulose } \\
\text { basis) }\end{array}$ & (\% on dried & $\begin{array}{l}\text { Lignin } \\
\text { basis) }\end{array}$ & (\% on dried & Moisture \% on wet basis & Ash (\% dried basis) \\
\hline Banana Peels & 9.4 & 34.8 & 4.5 & 85.7 & 12.9 \\
\hline Pineapple Peels & 11.1 & 22.4 & 6.5 & 75.1 & 11.8 \\
\hline Papaya Peels & 24.6 & 20.4 & 2.7 & 91.3 & 5.8 \\
\hline Mango Peels & 13.9 & 38.4 & 27.9 & 77.8 & 4 \\
\hline
\end{tabular}

Table 1: Compositional analysis of fruit wastes (\% on dried basis). 
(a)

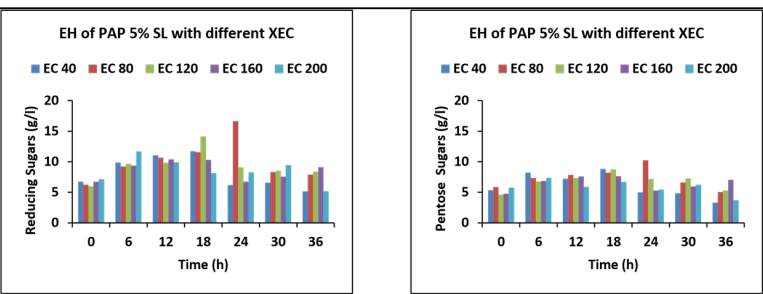

(b)

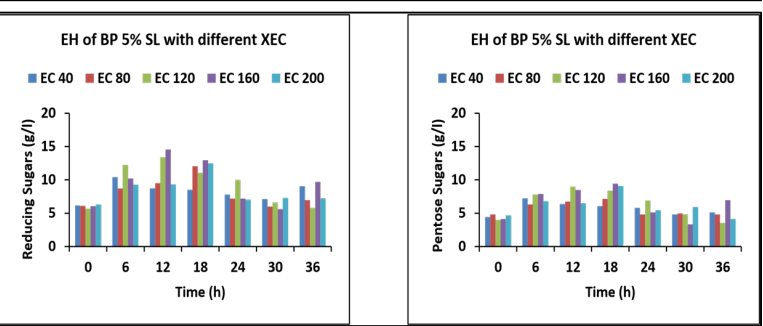

Figure 3: Estimation of TRS and PS content from (a) 5\% SL PAP and (b) $5 \%$ SL BP by using different concentration of commercial xylanase enzyme.

\section{Dilute acid hydrolysis of fruit wastes}

Studies were extended on dilute acid hydrolysis (AH) using 0.5-3\% $\mathrm{H}_{2} \mathrm{SO}_{4}$, for $30 \mathrm{~min}$ with $5 \%$ and $10 \%$ substrate loading (SL) respectively. Figure $4 \mathrm{a}$ shows the production of TRS and PS using 5\% SL and Figure $4 \mathrm{~b}$ shows the production of TRS and PS by using $10 \%$ SL. It was observed that the production of TRS (20.3 g/l) and PS 6.27 $\mathrm{g} / \mathrm{l}$ was maximum from PP using $1 \% \mathrm{H}_{2} \mathrm{SO}_{4}$. In case of $10 \% \mathrm{SL}$, the maximum TRS production of $31.46 \mathrm{~g} / \mathrm{l}$ and a low content of PS $3.1 \mathrm{~g} / \mathrm{l}$, was obtained from BP using $0.5 \% \mathrm{H}_{2} \mathrm{SO}_{4}$. This was followed by PAP (TRS $28.79 \mathrm{~g} / \mathrm{l}$ and PS $14.98 \mathrm{~g} / \mathrm{l}$ ), PP (TRS $21.5 \mathrm{~g} / \mathrm{l}$ and PS $9.3 \mathrm{~g} / \mathrm{l}$ ) and MP (TRS $15.5 \mathrm{~g} / \mathrm{l}$ and PS $5.5 \mathrm{~g} / \mathrm{l}$ ). It was interesting to observe that the use of $0.5 \% \mathrm{H}_{2} \mathrm{SO}_{4}$ for a soaking time of $30 \mathrm{~min}$ was sufficient for the hydrolysis of cellulosic and hemicellulosic contents of the fruit waste. However, the acidic hydrolysis also results in the formation of furfural and hydroxyl methyl furfural. These compounds are the inhibitors of fermentation of sugars. The use of higher concentration of $\mathrm{H}_{2} \mathrm{SO}_{4}$ leads to the production of more of these compounds from the degradation of sugars [15,20-22]. Studies were further extended by using $5 \%$ and $10 \%$ SL by employing $0.5-3 \% \mathrm{H}_{2} \mathrm{SO}_{4}$ for 90 min soaking time at room temperature. The results have been shown in Figures $4 \mathrm{c}$ and $4 \mathrm{~d}$. In the case of 5\% SL, the maximum TRS yields were obtained from PP (22.5 $\mathrm{g} / \mathrm{l}$ ) along with that of PS as $7.6 \mathrm{~g} / \mathrm{l}$. However, in case of $10 \% \mathrm{SL}$, the maximum TRS was observed form BP $(28.8 \mathrm{~g} / \mathrm{l})$ and PS $(3.2 \mathrm{~g} / \mathrm{l})$. This was followed by that from PAP of TRS $(24.98 \mathrm{~g} / \mathrm{l})$ and PS $(16.2 \mathrm{~g} / \mathrm{l})$. It was observed that the use of $0.5 \% \mathrm{H}_{2} \mathrm{SO}_{4}$ for a soaking time of $90 \mathrm{~min}$. was sufficient for the hydrolysis of fruit wastes. The lower yield of PS could be due to the reason that these sugars can undergo degradation even under milder acidic condition. Figure $4 \mathrm{e}$ and $4 \mathrm{f}$ show the yields of TRS and PS from fruit wastes using longer acidic hydrolysis times of $180 \mathrm{~min}$. Using SL of 5\% and $10 \%$, however, it was observed that the longer hydrolysis times did not improve the sugar yields. In fact, longer hydrolysis times would result in the further degradation of sugars to give furfural and hydroxymethyl furfural $[35,36]$. Interestingly, acidic hydrolysis was found to give good yield of total reducing sugars and the hydrolysates thus obtained were also subjected to the fermentation by using $S$. cerevisiae yeast.

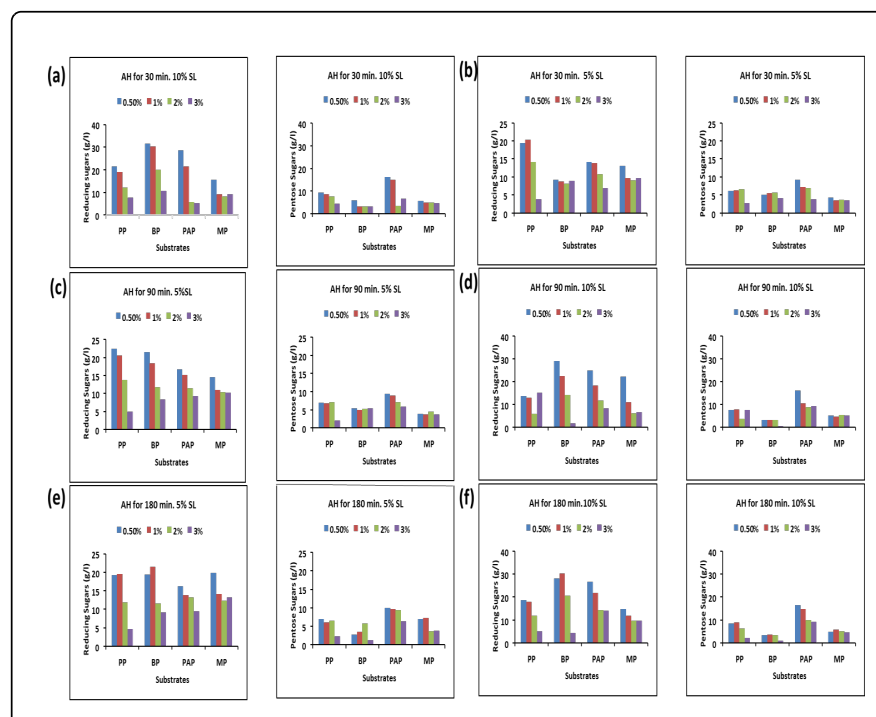

Figure 4: Estimation of TRS and PS by acid hydrolysis (AH) of different fruit peels for (a) 30 minutes using 5\% SL (b) 30 minutes using $10 \%$ SL (c) 90 minutes using 5\% SL (d) 90 minutes using 10\% SL(e) 180 minutes using 5\% SL (f) 180 minutes using 10\% SL.

\section{Mechanism of enzymatic hydrolysis}

It seems there is a need to improve the yields from sugars from the enzymatic hydrolysis of fruit wastes. In fact, the acidic hydrolysis gave higher yields of reducing sugars, therefore this showed that there is a need to improve the enzymatic hydrolysis of LCBs further for obtaining higher yields of reducing sugars. Presently, the studies were performed to increase the enzyme concentration as well as hydrolysis temperature up to $50^{\circ} \mathrm{C}$. The use of higher temperature would improve the kinetics of hydrolysis. However, this may also result in the degradation of the enzymes during hydrolysis, especially during the longer times. It was found that there are limitations on the action of both the enzymes (cellulase and xylanase) on the LCBs. One reason could be the inhibitions due to cellobiose and other product inhibitors formed. Actually, increase in the enzyme concentration would help in maintaining the hydrolysis by increasing the interaction between the glycosyls for degrading the anhydroglucan units through cleavages of $\beta-1$, 4' C-O-C linkages. Formation of cellobiose and other oligomers leads to the product inhibition of the enzymes. Therefore, there is a need to understand the mechanism of hydrolysis of LCBs in details for modifying the same further in order to improve the yields of reducing sugars from fruit wastes and other LCBs. Studies in the authors laboratory were carried out in the past on the production of different enzymes such as, cellulase, xylanase, $\beta-1,3$ gulanase, chitinase and cellobiase enzymes from the wheat litter decomposing fungi such as Alternaria tennisima, Aspergillus flavus, Fusarium moriliforme, Penicillium chrysogenum and Trichoderma viride. These were selected out of the 37 wheat litter decomposing fungi [18]. Different LCB substrates (about 14) including sugarcane bagasse and stems of latex bearing plants and trees were used as substrates for the biosynthesis of these biocatalysts in the solid state fermentation technique i.e., surface culture technique. The use of Penicillium chrysogenum showed the production of different hydrolase biocatalysts having good activities 
out of the different fungi studied. The enzymes showed the optimum activities at $45^{\circ} \mathrm{C}$ showed inhibitory effects due to the degradation of enzymes. Activities of these enzymes were maximum at the late lag phase of $P$. chrysogenum. However, $\beta-1,3$ glucanase and cellobiase enzymes showed good activities at the $5^{\text {th }}$ day of the surface culture phase. $P$. chrysogenum also produced active xylanase and chitinase enzymes. Therefore $P$. chrysogenum was found to be the potential candidate for producing a host of hydrolase biocatalysts which can be used for preparing the biocatalyst cocktails for the hydrolysis of LCBs. The authors feel that further studies of proteomics analysis [37] may be extended on the biocatalysts produced by $P$. chrysogenum. The folds of cellulosic fibers are loosened and opened (i.e., unfolded) by the action of different enzymes in concert and in a synergistic way. The continuous activities in the extracellular proteins on the last day of the surface culture was due to the increase of temperature and was a result of the release of cell separating enzymes such as avicellase, carboxymethyl cellulase, xylanase, cellobiase, chitinase etc. Therefore, these studies showed that a host of hydrolase enzyme biocatalysts can be obtained and these can be used to design a cocktail of enzymes to take care of inhibitors including cellobiose. In fact these studies have been further confirmed by the proteomics studies on the cellulase enzyme [37-40]. A number of proteins from the cellulolytic fungi have been reported and the research work on the mechanism of hydrolysis using cellulase enzyme is a topic of current research world over. In fact, understanding of fungal secretomes i.e., extracellular enzyme proteins would help in understanding their synergistic action and kinetics profiles.

Other studies from the authors, laboratory [19] showed how the structural architecture of the LCB materials changes during the saccharification. The studies of the pretreatments such as steaming, solvent extraction, acidic hydrolysis, delignification by using ligninase enzyme as well as that of the action of Phanerochaete chrysosporium on cellulosic materials in the LCBs were studied by performing the detailed SEM studies. It was that the delignification by using ligninase enzyme was the most effective in improving the yields of reducing sugars from the LCBs. It was found that the action of the ligninase enzyme had resulted in the formation of brittle notches with continuous cracks in the fiber surface. The action of the number of enzymes in the cellulase enzyme complex can begin from these spots, however, the enzymes act randomly in concert and in synergism. The substrate morphology changes as the fibers are cut by the unzipping of glycosidic C-O-C bonds and the deconstruction crystalline cellulosic structure and thus the surface area also increases. Pretreatments also lead to the loosening of the $\mathrm{H}$-bonding interactions between the different biopolymers. Moreover, the detailed mechanism of the enzymatic hydrolysis of LCBs is still a major topic of studies [41,42]. The studies from the authors' Laboratory had also reported the simultaneous production of reducing sugars during the surface culture of cellulolytic fungi on sugarcane bagasse [33]. The studies on the role of different monomeric, dimeric, oligomeric etc. sugars in inducing the production of cellulase enzyme by modifying and promoting the biosynthetic metabolic pathways in the cellulolytic fungi would help in understanding the function of different signalling molecules in the process. The interplay of different hydrolase biocatalysts with the glycosyls and the stepwise production of reducing sugars involve slower reactions. There is a need to extend further research in different systems biology areas such as genomics, transcriptomics, interactomics and of course on proteomics of hydrolase enzyme biocatalysts. This would permit the over-expression of the required enzymes for the effective, efficient and quicker hydrolysis of LCBs by using cellulase enzyme. Since the fruit wastes mostly did not contain much lignin (excepting mango peels) therefore, inhibitory effects due to the presence of lignin are minimum during the enzymatic hydrolysis of these wastes. The lignocellulosic $\mathrm{H}$-bonding and other intermolecular interactions in fruit wastes are mostly loose and therefore this is a suitable substrate and feedstock for the enzymatic hydrolysis.

\section{Fermentation of hydrolysates}

Fermentation of hydrolysates obtained from the enzymatic (using cellulase and xylanase enzymes and those from the acidic hydrolysis was carried out by baker's yeast ( $S$. cerevisiae). The results obtained from the hydrolysates prepared by the enzymes (XE and $\mathrm{CE}$ ) and by the use of dilute sulphuric acid of two substrates (i.e., BP and PAP) by baker's yeast ( $S$. cerevisiae) are shown in Figure $5 \mathrm{a}, 5 \mathrm{~b}$ and $5 \mathrm{c}$ and the $\%$ utilization of reducing sugars are depicted in Figure 5d. During the incubation period of $25 \mathrm{~h}$, the yield of bioethanol obtained from BP and PAP were found to increase gradually from the first $5 \mathrm{~h}$ to the $15 \mathrm{~h}$ with the banana and pineapple peels with cellulase hydrolysate giving the highest yield of $6.3 \mathrm{~g} / \mathrm{l}$ from banana peels, followed that of by pineapple peels as $4.59 \mathrm{~g} / \mathrm{l}$, However, the fermentation of xylanase hydrolysate gave $3.59 \mathrm{~g} / \mathrm{l}$ from the hydrolysate of pineapple peels after $20 \mathrm{~h}$ and this was followed by that from banana peels after $15 \mathrm{~h}$ of incubation as $3.13 \mathrm{~g} / \mathrm{l}$ ethanol yield.

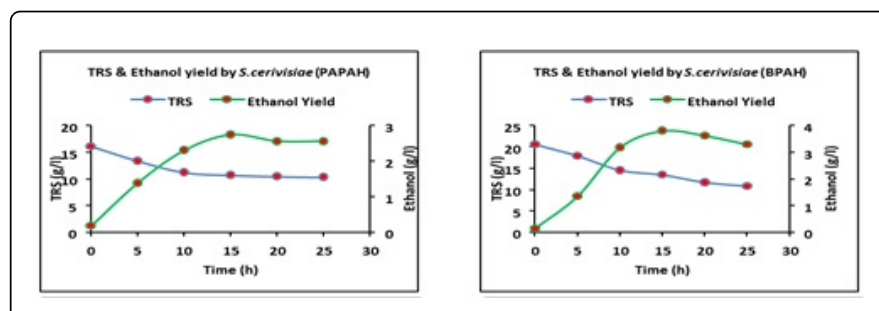

Figure 5a: TRS and Ethanol obtained in (PAPAH and BPAH) by using $S$. cerevisiae in SHF for $25 \mathrm{~h}$.
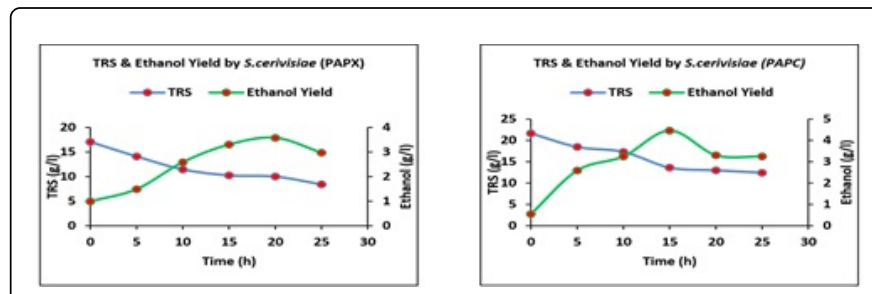

Figure 5b: TRS (XEH and CEH) and Ethanol obtained in PAPH by S. cerevisiae in SHF for $25 \mathrm{~h}$. 


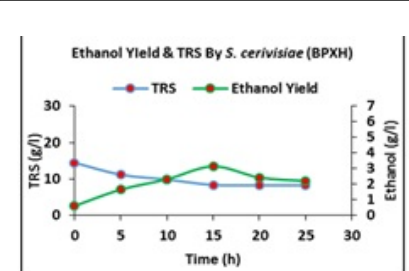

Xylanase Hydrolysate(XEH)

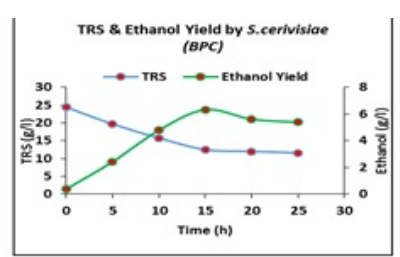

Cellulase Hydrolysate (CEH)
Figure 5c: TRS (XEH and CEH) and Ethanol obtained in BPH by $S$. cerevisiae SHF for $25 \mathrm{~h}$
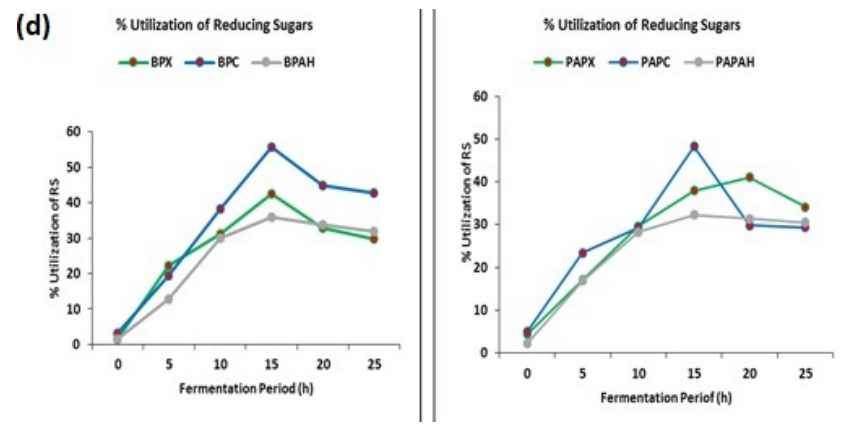

Figure 5d: Utilization of RS in BP and PAP (Acid, XE, CE) hydrolysates by $S$. cerevisiae.

\section{Comparison of the yield of bioethanol}

Since acidic hydrolysis of fruit peels showed higher fermentable sugars yield in comparison to those by the enzymatic hydrolysis (separate acidic hydrolysis and fermentation i.e., SHF), this showed that there is a need to engineer the cellulase enzyme for enhancing its action on the LCBs $[42,43]$. Recently the studies from the authors, laboratory have also found out that co-culture of two fungi i.e., Trichoderma reesei and Phanerochaete chrysosporium resulted in the production of an active cellulase enzyme which may have broad spectrum of biocatalytic activities as this would have a cocktail of several different hydrolase biocatalysts. Different cellulolytic fungi in the combination of two at a time were used in the co-culture experiments and there was symbiosis of these fungi in producing and secreting different enzymes and the enzymatic activities of the enzyme complex obtained were studied. It is proposed to carry out proteomics studies on these biocatalysts (in the secretomes).

There is also a need to increase the temperature of hydrolysis by using thermostable enzymes. In fact, Oljuigbe and Ogunyewo have recently reported on the enhanced production of thermostable crude cellulose enzyme from Sporothrix carnis by cultivating this on corn cobs [34]. The crude enzyme showed optimum activity at $80^{\circ} \mathrm{C}$. The authors feel that there is a need to extend the use of the thermostable enzymes on fruit wastes and agricultural wastes.

\section{Comparison of the studies with earlier work}

The present process of separate hydrolysis of mildly water pretreated fruit wastes by using cellulase and xylanase enzymes was convenient and simpler and this can be easily extended for use on other different fruit wastes, agricultural, forest, municipal etc. wastes. The present results were compared with those obtained by earlier workers through different hydrolytic processes. The results were found to be comparable. The ethanol yield obtained from pineapple peels in this study related favourably with results reported by Itelima et al. [3] who had reported obtaining the same after 6 day period of simultaneous saccharification and fermentation (SSF) process. Utilization of substrates during fermentation in this study are comparable favourably with those of Shyam Kumar et al. [43] on the hydrolysis of banana peels and pineapple peels which was $55.8 \%$ for cellulase hydrolysate of banana peels followed by that of pineapple peels cellulase hydrolysate of $48.3 \%$, followed by that of xylanase hydrolysate fermentation, and these might have been inclined by several factors such as hemicelluloses, fiber, lignin and pectin complex. It has been observed that acid hydrolysate produced less ethanol than enzymatic hydrolysate and very less $36 \%$ (3.82 g/l ethanol yield) with banana peels and 33\% $(2.75 \mathrm{~g} / \mathrm{l}$ ethanol yield) from pineapple peels from the utilization of reducing sugar by $S$. cerevisiae during fermentation for $25 \mathrm{~h}$ than enzymatic hydrolysis under same condition. These results are in good agreement with Arumugam and Manikandan [8]. At the start production of ethanol was very low. The residual sugar also reduced considerably due to the effectiveness of the strains in consumption of reducing sugars. The results from this study clearly show that in all the substrates the concentration of the reducing sugars decreased gradually with time as sugar utilization reached at its climax. The highest reducing concentration $(11.4 \mathrm{~g} / \mathrm{l})$ was detected in pineapple peels after $25 \mathrm{~h}$ of the fermentation period in cellulase hydrolysate.

\section{Scope of future work}

In fact, the acidic hydrolysis of PAP and BP had given good yields of TRS and PS, however, the fermentation of the acidic hydrolysates yielded poor bioethanol. This showed that yeast was being inhibited by the degradation products such as furfural, hydroxymethyl furfural, levulinic acid etc. Therefore, there is a need to extend further research work on engineering the $S$. cerevisiae yeast $[44,45]$ for withstanding this inhibition. Moreover, the $S$. cerevisiae yeast should be modified to act on all the different sugars including arabinose, mannanose, galactose and xylose obtainable from the hemicelluloses besides glucose.

There is also a need to increase the rate of enzymatic hydrolysis of biomass (including fruit wastes) by using the enzyme cocktails containing cellulase and xylanase enzymes as has been reported by $\mathrm{Hu}$ et al. [2]. The use of cocktail of enzymes in fruit waste hydrolysis may reduce the enzyme loading also.

The studies on the proteomics of the fungal secretomes should be extended to understand the nature of hydrolase biocatalysts produced by fungi or bacteria. The studies of the mechanism of the action of biocatalysts during the enzymatic hydrolysis of LCBs would also help in understanding the synergism in the actions of different biocatalysts involved. Moreover, the cost of production of biocatalysts as well as of pretreatments should be reduced. The major bottleneck in the case of fruit wastes is their management i.e., the collection, transportation and storage for the processing to obtain bioethanol.

There may also be a need to introduce post hydrolysis using acids after the enzymatic hydrolysis of LCBs, besides some cases where the use of prehydrolysis using dilute acids [15] before the enzymatic hydrolysis has also been performed. This three step treatment may help in recovering more reducing sugars from the LCBs. 


\section{Utilization of spent residues}

The spent fruit residues obtained from the hydrolysis processes may be used as feedstocks for the biogas digester to obtain biogas and manure. These may also be used as an animal fodder after removing toxic chemicals if any. Alternately these may be composted or these may be utilized for the traditional uses of fruit wastes as are being practiced presently.

\section{Conclusions}

Simple water soaking and then steaming can afford the recovery of reducing sugars from fruit wastes. Amongst fruit wastes, banana and pineapple peels hold better potential of yielding bioethanol through enzymatic hydrolysis followed by fermentation using Saccharomyces cerevisiae yeast. Enzymatic hydrolysis route is better than acidic hydrolysis process for the production of bioethanol though acidic hydrolysis gave higher yields of total reducing sugars and pentose sugars. There is a need to understand the mechanism of the enzymatic hydrolysis of lignocellulosic biomass. There is a good potential of using fruit wastes for the production of bioethanol through enzymatic hydrolysis process. Production of bioethanol can be integrated with the biorefineries where bioethanol would be produced by the hydrolysis of LCBs such as agroresidues, forest wastes or municipal wastes, fruit wastes. This would ultimately pave the way towards the establishment of bio economy.

\section{References}

1. Sharma DK (2006) Bioprospecting for drug research and functional foods for prevention of diseases-Role of flavonoids in drug development. J Sci Ind Res 2: 391-401.

2. Hu J, Arantes V, Saddler JN (2011) The enhancement of enzymatic hydrolysis of lignocellulosic substances by addition of accessory enzymes, such as xylanase: is an addition or synergistic effect? Biotechnol Biofuels 4: 36 .

3. Itelima J, Onwulin F, Onwulin E, Isaac O, Forji S (2013) Bio-ethanol production from banana, plantain and pineapple peels by simultaneous saccharification and fermentation process. Int J Environ Sci Develop 4: 2137.

4. Singh KA, Rath S, Kumar Y (2014) Bio-Ethanol production from banana peel by simultaneous saccharification and fermentation process using cocultures Aspergillus niger and Saccharomyces cerevisiae. Int J Curr Microbiol Appl Sci 3: 84-96.

5. Grohman K, Manthon JA, Cameron RG, Buslig BK (1995) Fermentation of sugars in orange peel hydrolysates to ethanol by recombinant Escherichia coli KO11. Appl Biochem Biotechnol 51: 423-435.

6. Mishra J, Kumar D, Samanta S, Kumar M (2012) A comparative study of ethanol production from various agroresidues by using Saccharomyces cerevisae and Candida abicans. J Yeast Fungal Res 3: 12-17.

7. Reddy GV, Babu PR, Komaraiah P, Roy KRRM, Kothari IL (2003) Utilization of banana waste for the production of lignolytic and cellulolytic enzymes by solid substrate fermentation using two Pleurotus species (P. ostreatus and P.sajor-caju). Process Biochem 38: 1457-1462.

8. Arumugam R, Manikandan M (2011) Fermentation of pretreated hydrolysates of banana and mango fruit wastes for ethanol production. Asian Journal of Experimental Biol Sci 2: 246-256.

9. Ban Koffi L, Han YW (1990) Alcohol production from pineapple waste. World J Microbiol Biotechnol 6: 281-284.

10. Patrisha P, Hernandez R, William TF, Benjamin GE, Andro HM (2001) A sectrophotometric method for quantitative determination of xylose in fermentation medium. Biomass Bioenergy 35: 2814-2821.

11. Sun Y, Cheng J (2002) Hydrolysis of lignocellulosic materials for ethanol production: a review. Bioresour Technol 83: 1-11.
12. Manikandan K, Saravanan V, Viruthagiri T (2008) Kinetics studies on ethanol production from banana peel waste using mutant strain of Saccharomyces cerevisiae. Indian J Biotechnol 7: 83-88.

13. Shilpa C, Malhotra G, Chanchal C (2013) Alcohol production from fruit and vegetable waste. Int J Appl Eng Res 8: 1749-1756.

14. Alemayehu $\mathrm{G}$ (2014) Bioethanol production from fruit wastes and factors affecting its fabrication. Int J Chem Nat Sci 2: 132-140

15. Sharma DK (1989) Two-step process for selective production of fermentable sugars and ethanol from biomass residues (agricultural wastes). Cellul Chem Technol 23: 45-51.

16. Sharma DK, Das K (1992) Enzymatic hydrolysis of chemically pretreated bagasse. Ind Chem Eng 34: 63-69.

17. Sharma DK, Tiwari M, Behera BK (1994) A review of integrated processes to get value added chemicals and fuels from petrocrops. Bioresour Technol 49: 1-6.

18. Sharma DK, Tiwari M, Behera BK (1995) Solid State fermentation of new substrates for production of cellulase and other biopolymer hydrolysing enzymes. Appl Biochem Biotechnol 51: 495-500.

19. Behera BK, Arora M, Sharma DK (1996) Scanning electron microscopic (SEM) studies on structural architecture of lignocellulosic materials of Calotropis procera during its processing for saccharification. Bioresour Technol 58: 241-245.

20. Singh A, Das K, Sharma DK (1984) Integrated process for production of furfural, xylose, glucose, and ethanol by two step acid hydrolysis. Ind Eng Chem Prod Res Dev 23: 257-262.

21. Singh A, Das K, Sharma DK (1984) Production of reducing sugars from bagasse and rice husk by acid hydrolysis. Agricultural Wastes 9: 131-145

22. Singh A, Das K, Sharma DK (1984) Production of xylose, furfural, glucose and ethanol from agricultural residues. J Chem Technol Biotechnol 34: 51-61.

23. Sharma DK, Mbise HA, Singh SK (1990) Production of biocrude and fermentable sugars from Croton bonplandianum, and fermentation of hydrolysate to get ethyl alcohol. Cellul Chem Technol 24: 193-200.

24. Sharma DK, Goldstein IS (1990) Reactivity towards phenol of lignin from the hydrolysis of sweetgum wood with concentrated sulphuric acid. J Wood Chem Technol 10: 379-386.

25. Sharma DK (2015) Emerging biomass conversion technologies for obtaining value-added chemicals and fuels from biomass. Proc Indian Nat Sci Acad 81: 755-764.

26. Liguori R, Ventorino V, Pepe O, Faraco V (2016) Bioreactors for lignocelluloses conversion into fermentable sugars for production of high value products. Appl Microbiol Biotechnol 100: 597-611.

27. Updegraff DM (1969) Semi micro determination of cellulose in biological materials. Anal Biochem 32: 420-424.

28. Goering HK, Van Soest PJ (1970) Forage Fiber Analysis. USDA Agricultural Research Service. Handbook number 379. US Department of Agriculture. Superintendent of Documents, US Government Printing Office, Washington, DC.

29. Miller GL (1959) Use of dinitrosalicylic acid reagent for determination of reducing sugar. Anal Chem 31: 426-428.

30. Onsori H, Zamani MR, Matallebi M, Zarghami N (2005) Identification of overproducer strain of endo- $\beta-1,4$-glucanase in Aspergillus Species: Characterization of crude carboxymethyl cellulose. Afr J Biotechnol 4: 26-30.

31. Jahid M (2015) Hydrolysis of fruit wastes for bioethanol production. M. Tech Dissertation, Indian Institute of Technology Delhi, New Delhi, India.

32. Williams MB, Reese HD (1950) Colorimetric determination of ethyl alcohol. Anal Chem 22: 1556-1561.

33. Sharma DK, Niwas S, Behera BK (1991) Solid state fementation of bagasse for the production of cellulose enzyme from the cellulolytic fungi and extent of simultaneous production of reducing sugars. J Microbial Biotechnol 6: 7-14.

34. Olajuigbe FM, Ogunyewo OA (2016) Enhanced production and physicochemical properties of thermostable crude cellulose from 
Citation: Jahid M, Gupta A, Sharma DK (2018) Production of Bioethanol from Fruit Wastes (Banana, Papaya, Pineapple and Mango Peels) Under Milder Conditions. J Bioprocess Biotech 8: 327. doi:10.4172/2155-9821.1000327

Page 11 of 11

Sporithrix carnis grown on corn cob. Biocatal Agric Biotechnol 7: 110-117.

35. Sharma DK, Sahgal PN (1982) Production of furfural from agricultural wastes using presssurized water in a batch reactor. J Chem Tech Biotech 32: 666-668.

36. Sharma DK, Sahgal PN (1983) Elevated temperature hydrolysis of rice husk with pressurized water in a semibatch process. Cellul Chem Technol 17: $655-658$.

37. Li A, Wang R, Li X, Fan O, Guo K, et al. (2016) Proteomics profiling of cellulose-aid-extracted proteins for functional identification of cellulose synthase complex and their potential associated components in cotton. Scientific Reports.

38. Kim Y, Nandakumar MP, Marten MR (2007) Protemics of filamentous fungi. Trends Biotechnol 25: 395-400.

39. Bouws A, Wattenberg A, Zorn H (2008) Fungal secretomes -natures toolbox for white biotechnology. Appl Microbiol Biotechnol 80: 381-388.
40. Chandrawat S, Lipton MS, Purvine SO, Uppugundla S, Gao D, et al. (2011) Proteomics-based compositional analysis of complex cellulose hemicellulase mixtures. Journal of Proteomics Research 10: 4365-4372.

41. Green ER, Himmel ME, Beckman GT, Tan Z (2015) Glycosylation of cellulose: Engineering better enzymes for biofuels. Adv Carbohydr Chem Biochem 72: 63-112.

42. Elizabeth AM (2015) Engineering Cellulase Enzymes for Bioenergy. University of California, Berkeley, USA.

43. Shyam Kumar R, Gandhi M, Rajeshwari R, Harikrishnan H (2011) Utilization of waste ripe banana and peels for bioethanol production using Saccharomyces cerevisiae. J Biosci Res 2: 67-71.

44. Nevoigt E (2008) Progress in metabolic engineering of Saccharomyces cerevisae. Microbiol Mol Biol Rev 72: 379-412.

45. Jonsson LI, Martin C (2016) Pretreatment of lignocellulose: Formation of inhibitory byproducts and strategies for minimizing their effects. Bioresour Technol 199: 103-112. 